\title{
WestVirginiaUniversity
}

THE RESEARCH REPOSITORY @ WVU

Graduate Theses, Dissertations, and Problem Reports

2003

\section{Linear expansion of dental stone after its final set and beyond two hours}

Marcos Cid Galano

West Virginia University

Follow this and additional works at: https://researchrepository.wvu.edu/etd

\section{Recommended Citation}

Cid Galano, Marcos, "Linear expansion of dental stone after its final set and beyond two hours" (2003). Graduate Theses, Dissertations, and Problem Reports. 1722.

https://researchrepository.wvu.edu/etd/1722

This Thesis is protected by copyright and/or related rights. It has been brought to you by the The Research Repository @ WVU with permission from the rights-holder(s). You are free to use this Thesis in any way that is permitted by the copyright and related rights legislation that applies to your use. For other uses you must obtain permission from the rights-holder(s) directly, unless additional rights are indicated by a Creative Commons license in the record and/ or on the work itself. This Thesis has been accepted for inclusion in WVU Graduate Theses, Dissertations, and Problem Reports collection by an authorized administrator of The Research Repository @ WVU. For more information, please contact researchrepository@mail.wvu.edu. 


\title{
LINEAR EXPANSION OF DENTAL STONE AFTER ITS FINAL SET AND BEYOND TWO HOURS
}

\author{
Marcos Cid Galano, D.D.S.
}

\author{
Thesis submitted to the \\ School of Dentistry \\ At West Virginia University \\ In partial fulfillment of the requirements \\ for the degree of
}

\author{
Master of Science \\ In \\ Prosthodontics
}
Mark W. Richards D.D.S. M.ED. (Co-Chair)
Keith E. Kinderknecht D.M.D. (Co-Chair)
Mohessen Ghalichebaf D.D.S., M.S.

Morgantown, West Virginia

2003 


\title{
ABSTRACT
}

\section{Linear Expansion of Dental Stone After its Final Set and Beyond Two Hours}

\author{
Marcos Cid Galano, D.D.S.
}

When accuracy and strength are required in fabricating working casts improved dental stones are recommended. The main variable affecting this accuracy is linear setting expansion. In this research study the linear setting expansion of three commonly used improved dental stones were compared over an extended 2-week period. Hard Rock, Silky Rock and Prima-Rock were vacuum mixed following manufacturers instructions. Five specimens of each stone were measured for linear expansion using a SAM EMI100 Expansion measuring Device. Expansion measurements were made at 10 and 30 minutes, 2, 24, 48, 72, and 120 hours. The gathered data were subjected to a two way ANOVA and the Tukey Multiple Range Test. The ADA specification \#25 measures expansion over a 2-hour span. Continued dimensional changes may affect the accuracy of the final cast. The final fit of a restoration is determined by the accurate duplication of important oral structures and tooth preparations. 


\section{DEDICATION}

I would like to dedicate this project to my parents Dr. Ernesto Cid Garcia and Dr. Marta Alicia Galano Masso. You have shown and proven to me through the years the true meaning of unconditional love. Thank you for all of the lessons that you have taught me. Everything that I am and all that I will become in this life I truly owe to you. You have shown me where my future is, but you have never let me forget where I come from and how integral that is to who I am.

To all that is magical in my life. May it be that way forever! 


\section{ACKNOWLEDGEMENTS}

I would like to thank the following people for changing and enhancing my life professionally as well as personally:

Dr. Mark W. Richards, for providing me with the opportunity to have partaken in this specialty program when no one agreed with him. Thank you for always being positive, helpful, and willing to bestow your undying knowledge of Prosthodontics upon me. More than anything, thank you for being a friend and a colleague.

Dr. Mohssen Ghalichebaf, for the inspiration that you have provided in showing me that prosthetics in dentistry can truly change and save a patient's life. Thank you for all that you have taught me through the years and all of the advice that you have shared. You have truly shown me the path in which I should direct my profession.

Dr. Keith Kinderknecht, for the idea of doing this research project as well as for all of your help. Thank for the providing the leadership that we needed in these times of trouble.

Dr. Stephen Kwiatkowski, for showing me all of the small details that most would overlook when dealing with esthetics in Prosthodontics. Thank you for sharing your infinite knowledge and teaching me the art and beauty of cosmetic dentistry.

Dr. Mayur M. Patel, for the insurmountable friendship and support that you have given me for the last two years of my residency. Thank you for sharing your cases and knowledge with me and for providing me with unconditional support. 
I wish happiness and prosperity upon all of you and may your endeavors in life take you to great places. You are all a part of what I have become and will be with me personally and professionally for the rest of my life. 


\section{TABLE OF CONTENTS}

\begin{tabular}{|c|}
\hline LINEAR EXPANSION OF DENTAL STONE AFTER ITS FINAL SET AND \\
\hline HOURS \\
\hline ABSTRACT. \\
\hline DEDICATION. \\
\hline ACKNOWLEDGEMENTS.. \\
\hline TABLE OF CONTENTS. \\
\hline LIST OF TABLES.. \\
\hline LIST OF FIGURES ... \\
\hline CHAPTER I: INTRODUCTION. \\
\hline BACKGROUND ... \\
\hline STATEMENT OF THE PROBLEM. \\
\hline SIGNIFICANCE OF THE PROBLEM... \\
\hline NULL HYPOTHESIS ........... \\
\hline DEFINITIONS OF TERMS ... \\
\hline ASSUMPTIONS \\
\hline LIMITATIONS ................... \\
\hline DELIMITATIONS .............. \\
\hline CHAPTER II: LITERATURE REVIEW . \\
\hline CHAPTER III: MATERIALS AND METHODS . \\
\hline CHAPTER IV: RESULTS AND DISCUSSION \\
\hline RESULTS .............................. \\
\hline DISCUSSION.. \\
\hline CHAPTER V: ..... \\
\hline SUMMARY AN \\
\hline SUMMARY. \\
\hline CONCLUSIONS. \\
\hline RECOMMENDATIONS.. \\
\hline LITERATURE CITED ......... \\
\hline TUIUUM \\
\hline
\end{tabular}




\section{LIST OF TABLES}

Tlable 1. ADA Specification 25 for Dental Gypsum Products....................................... 26

Table 2. Manufacturers Specifications for Improved Dental Stones ............................26

Table 3. Raw Data for Silky Rock ............................................................................. 31

Table 4. Raw Data Prima Rock....................................................................... 32

Table 5. Raw Data for Hard Rock ........................................................................... 33 


\section{LIST OF FIGURES}

Figure 1. Comparison of Mean Linear Expansion .................................................. 34 


\section{CHAPTER I: INTRODUCTION}

\section{BACKGROUND}

Ancient man used gypsum to make bowls, cups, and sculptures. The Greeks used a transparent form for windows in their temples to filter sunlight, cool the buildings, and produce a moonlight effect. The Greeks called it Selene, after the goddess of the moon. The name selenite is still used for translucent forms of the material. The Romans used it to line tomb walls and make decorative vases and urns. Artists of the Renaissance made moldings in cathedrals and palaces and carved decorative ceilings from it. Today gypsum is the major component of wallboard. Dental plaster is chemically the same as wall plaster but with much higher purity ${ }^{1}$.

Gypsum products probably serve the dental profession for more diversified uses than any other materials in dentistry. Dental plaster, stone, high-strength/high-expansion stone, and casting investment materials constitute this group of products, which are all closely related. With slight modification, gypsum products are used for several different purposes. For example, as impression plaster, these materials can be used to take impressions of edentulous mouths or to mount casts. As dental stone, they are used to form a die that duplicates the oral anatomy when poured into any type of impression. Gypsum is also used as a binder for silicate investments for casting gold and low-melting nickel-chromium alloys, as well as soldering investment. These products are used also as mold material for processing complete dentures. The main reason for such diversified use is that the properties of gypsum materials can be easily modified, as well as their cost effectiveness. The mineral gypsum has commercial importance as a source of plaster of Paris. ${ }^{1}$ 
Most gypsum products are obtained from natural deposits. Gypsum is the dihydrate form of calcium sulfate, $\mathrm{CaSO}_{4} 2 \mathrm{H}_{2} \mathrm{O}$. Upon heating, it loses $1.5 \mathrm{~g}$ mol of its $2 \mathrm{~g}$ mol of $\mathrm{H}_{2} \mathrm{O}$ and is converted to calcium sulfate hemihydrate, $\mathrm{CaSO}_{4}{ }^{1 / 2} \mathrm{H}_{2} \mathrm{O}$, sometimes written $\left(\mathrm{CaSO}_{4}\right)_{2} \mathrm{H}_{2} \mathrm{O}$. When calcium sulfate hemihydrate is mixed with water, the reverse reaction takes place, and the calcium sulfate hemihydrate is converted back to calcium sulfate dihydrate. ${ }^{1}$

The reaction is exothermic, and whenever $1 \mathrm{~g}$ mol of calcium sulfate hemihydrate is reacted with $1.5 \mathrm{~g}$ mol of water, $1 \mathrm{~g}$ mol of calcium sulfate dihydrate is formed, and 3900 calories are developed. ${ }^{1}$ Depending upon the material composition, all gypsum products undergo some amount of linear expansion during and after their final set.

The four important types of relatively pure gypsum products used in dentistry are classified as model plaster, dental stone, high-strength stone, and high-strength/highexpansion dental stone, or alternatively as Types II, III, IV, and V in revised ANSI/ADA Specification No. 25 (ISO 6873). ${ }^{2}$ Although these types have identical chemical formulas of calcium sulfate hemihydrate, $\mathrm{CaSO}_{4} \frac{1}{2} \mathrm{H}_{2} \mathrm{O}$, they possess different physical properties, which makes each of them usable for a different purpose in dentistry. ${ }^{1}$

Types IV and V are produced when the dehydration is accomplished by adding another chemical, as by boiling in a $30 \%$ calcium chloride solution, after which the chlorides are washed away with hot water $\left(100^{\circ} \mathrm{C}\right)$ and ground to the desired fineness. The calcium sulfate hemihydrate in the presence of $100^{\circ} \mathrm{C}$ water does not react to form calcium sulfate dihydrate because at this temperature their solubilities are the same. ${ }^{1}$

Detailed reproduction of the oral structures is an important fabrication step and the physical properties of the cast or die can impact the final fit of the restoration. 
Continued linear setting expansion of ADA type IV and V dental stones may compound the error inherent in the multi-step fabrication procedure of a cast restoration. The accuracy of these stones is dependent on a known and predictable amount of expansion and long-term dimensional stability of the casts. New high expansion stones and resinmodified stones are being advocated as die stones for fixed prosthodontics. These stones are being introduced to improve the accuracy, stability, abrasion resistance and strength of existing materials. The range of expansion of the new and existing stones ranges from $.08 \%-.28 \% .^{2}$ 


\section{STATEMENT OF THE PROBLEM}

Continued linear expansion of ADA Type IV and V dental improved stones may compound the error inherent in the multi-step fabrication procedure of a cast restoration. 


\section{SIGNIFICANCE OF THE PROBLEM}

Many dental improved stones are used in the fabrication of master casts for the construction of dental prosthesis. Detailed reproduction of the oral structures is an important fabrication step and the physical properties of the cast or die can impact the final fit of the restoration. These casts must be of the utmost accuracy in order for the fabricated prosthesis to transfer to the patient's mouth properly. Linear setting expansion is one variable that greatly affects the accuracy of a master cast or a die. Since prosthesis are not usually fabricated during the first two hours after the master cast is poured, then there is a further chance the improved stones undergo further linear setting expansion and the final prosthesis are therefore affected. This can affect how much adjustment the dentist, at the insertion appointment, must do and can also affect the quality of the intimate fit necessary in certain dental prosthesis. With an accurate fit of the dental prosthesis problems such as caries due to marginal leakage at the cement line as well as alterations in occlusion can be minimized if not avoided. If expansion of dental stone is not accounted for, then recurrent marginal caries as well as incorrect alterations in the patient's occlusion can lead to clinical failure of dental prosthesis (removable as well as fixed). This is a significant problem to investigate because it can lead to choosing the most linearly stable stone over time. Fabrication of master casts and dies could then result in a more clinically successful prosthesis that is more comfortable for the patient and easier to insert without having to alter its processed structure. 


\section{NULL HYPOTHESIS}

None of the dental stones (Vel-mix, Die-keen, Jade stone, Resin rock, and GC

Fuji rock) will show higher linear setting expansion subsequent to the two-hour final set linear expansion measurements. 


\section{DEFINITIONS OF TERMS}

Gypsum: $\quad$ The natural hydrated form of calcium phosphate, $\mathrm{CaSO}_{4} \mathrm{H}_{2} \mathrm{O}$ gypsum dihydrate. ${ }^{3}$

Type II Dental A form of calcium sulfate hemihydrate that is a fibrous aggregate

Stone:

of fine crystals with capillary pores that are irregular in shape and porous in character. ${ }^{3}$

Working time: The time available to use a workable mix, one that maintains an even consistency that may be manipulated to perform one or more tasks. $^{3}$

Setting Time: $\quad$ The time that elapses from the beginning of mixing until the material hardens. ${ }^{3}$

Mixing Time: $\quad$ The time from the addition of the powder to the water until mixing is completed. ${ }^{3}$

Linear Setting The linear dimensional increase that occurs concurrent with the Expansion: hardening of various materials, such as plaster of Paris, dental stone, die stone, and dental casting investment. ${ }^{3}$

Diagnostic Cast: A life-size reproduction of a part or parts of the oral cavity and/or facial structures for the purpose of study and treatment planning. ${ }^{3}$

Working Cast: A life-size likeness of some desired form. It is formed within or is a material poured into a matrix or impression of the desired form. ${ }^{3}$

Type III Dental The form of calcium sulfate hemihydrate with physical properties

Stone:

superior to dental plaster. This form consists of cleavage

fragments and crystals in the form of rods or prisms, and is 
therefore more dense than dental plaster. ${ }^{3}$ Set gypsum that is calcined under steam pressure, forming a better quality of crystallized calcium sulfate hemihydrate. This was patented as alpha gypsum. Type III stone has a minimum 1-hour compressive strength of 20.7 Mpa, but does not exceed 34.5 Mpa. It is mainly intended for the construction of casts in the fabrication of full dentures that fit soft tissues. ${ }^{4}$

Type IV Dental

Stone:

Type V Dental

Stone:

Water to Powder

Ratio:

Dimensional

Stability:

SAM EMI100
A dental stone with strength, hardness, and minimum setting expansion. This is obtained with an alpha-hemihydrate of the

Densite type, giving a cuboidal shaped particle and reduced surface area. ${ }^{4}$ Type IV dental stone is used for the production of a dental die which is the positive reproduction of the form of a prepared tooth in any suitable substance. $^{3}$ attained by making it possible to lower the Water to powder ratio. ${ }^{4}$ The amount of water and hemihydrate powder that has been gauged accurately by weight. ${ }^{1}$

The ability of a material to maintain its original size and shape.

Dimensional changes during setting that have been measured directly and indirectly using confined and free-standing specimens in various geometric shapes. ${ }^{1}$

Expansion Measuring Device: An apparatus used to measure the setting expansion of dental materials, such as gypsum, etc... 
ANOVA test:

\section{Tukey multiple}

comparison test:
An analysis of variance uniquely comparing two different

estimates of the population variance to test a hypothesis

concerning the population means. ${ }^{5}$

A statistical test used to test all possible comparisons of means.

The honestly significant difference (HSD) is computed and all

differences are compared to the HSD. Those whose differences

exceed the HSD are considered statistically different. ${ }^{5}$ 


\section{ASSUMPTIONS}

One major assumption will be observed in this study of stone expansion. This assumption is that many working dental casts do sit a period of time (days and weeks) before any type of indirect restoration is fabricated upon them. 


\section{LIMITATIONS}

There are four major limitations to the subject at hand being researched. The first of these limitations is that the air temperature in the laboratory may differ for the collection of data on different stones. The second major limitation may be that humidity in the air may differ inside the laboratory for the collection of data on different dental stones being measured. And the third and final limitation to the study is that air quality may alter the stability of the stone being analyzed. Air quality refers to the amount of dust particles as well as gypsum particles that may be present in the laboratory where the study is being carried out. And fourth, samples of stone will not be measured simultaneously in order to follow previous project protocol. 


\section{DELIMITATIONS}

Three major delimitations will exhibited as part of this research study. First, handling of improved stone products will be comparable to that of a dental laboratory setting. This refers to the fact that distilled water that would normally be used will apply as well as the same type of equipment that is used in the dental laboratory. Secondly, the powder will be pre-packaged and the water is to be measured out by the researcher. And finally, only three brands of dental improved stone will be used although there are many more different brands available. 


\section{CHAPTER II: LITERATURE REVIEW}

The products of gypsum that are being studied come generally from plaster of Paris and stone materials. The theory of setting, after almost two hundred years of intensive study, is still a controversial issue, with the colloidal explanation being supported and diluted most recently. Dimensional changes as a result of setting have been studied by volumetric contraction measurements with the explanation that the presence of the contraction results in a porosity formation within the setting mass. Studies of the dimensional behavior after setting indicate no appreciable changes as a result of room temperature when handling. Erosion of the surface, however, is still an upsetting factor to the stability of dimension. Several investigators have studied strength and hardness of gypsum materials. But the most promising efforts in the field of mechanical properties involves the study of the resistance to abrasion of dental stones as used in inlay die purposes. $^{6}$

All dental stones used by dentists and laboratories are based upon calcium sulfate hemihydrate. Commercial stone contains inert pigments as well as salts such as potassium sulfate or tartrate and sodium citrate to reduce setting expansion and control setting time. ${ }^{7}$ Although gypsum products have been successfully used in dentistry for many years, the setting mechanisms, as calcium sulfate hemihydrate is converted to the dihydrate form, are not completely understood. Particularly puzzling is the anomalous expansion during set. It is known that thick mixes of hemihydrate and water expand more than do thin mixes, although thick mixes have less porosity than do thin mixes. On theoretical and experimental grounds, the setting reaction of dental stone should cause a $7.11 \%$ decrease in the volume of the constituents. Actually, although a small initial 
contraction may occur, dental stone undergoes a net expansion on setting. Although the dimensional change is somewhat dependent on the measuring method, in all cases, setting dental stone is expanded with respect to the predicted theoretical magnitude of contraction. ${ }^{8}$ This research study will focus on the expansion of dental stone. As a preamble to the study, the literature on stone expansion, as well as how to measure this expansion of stone, will be reviewed along with some different investigations on properties and characteristics of dental stone.

It has been proposed that the expansion of dental stone is caused by the impingement of growing crystals producing an outward thrust. This hypothesis is somewhat satisfying in that it qualitatively accounts for the difference in expansion of thick versus thin mixes. Thick mixes have more crystals impinging, hence more outward thrust and more

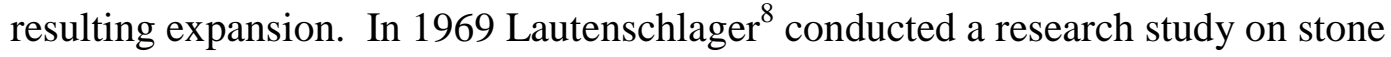
expansion in which he used calculations based on apparent density measurements and Xray diffraction data to study possible mechanisms causing thick mixes of setting dental stone to expand more than thin mixes but to have less total porosity to occupy the expanded space. His findings led him to hypothesize that micropores are formed in the wake of impinging dihydrate crystals. Thicker mixes of stone have more impingement and hence expansion than thinner mixes, but they also have more micropores to fill the expanded space. Later in the setting process, the evaporation of excess water eventually accounts for the total porosity of thinner mixes being greater than that of thicker mixes. In his findings, failure of the X-ray diffraction peaks to shift position or broaden with changing W/P ratio indicated that no gross differences in crystal strain were present. Therefore the impingement forces of the growing crystals are not large enough to 
produce any significant volume changes in the dihydrate crystals themselves limiting setting expansion. ${ }^{8}$

In 1964 Combe and $\mathrm{Smith}^{9}$ conducted a study comparing some of the mechanical characteristics of various model stones with that of die stones. Accurate proportions of the stone and water at room temperature were mixed in a hand operated mechanical spatulator using 100 turns in 30 seconds. Vicat setting time was determined as the time from the start of mixing when a $1 \mathrm{~mm}$ square needle under a load of $300 \mathrm{~g}$. Linear setting expansion was measured using a trough and dial gauge apparatus. Compressive strength was measured on specimens 0.5 inches in diameter and 1 inch high cast in a brass mould with mechanical vibration. His results led him to conclude that there is little support for the classification of these stones on the basis of mechanical properties. The superior hardness and strength of some type III stones over some of the type IV stones is probably due to better formulation offsetting the lower water/powder ratio. These considerations suggest that the selection of a stone from those available depends upon the particular application. Most of the materials would be satisfactory for general use although it is clear from the data that adequate working time coupled with good fluidity for a low water powder ratio represent the best choice from among materials which are economically comparable. ${ }^{9}$ Sweeney and Taylor ${ }^{10}$ presented a method of determining the dimensional changes in gypsum dental products. As part of the program of research on the gypsum products, a preliminary study was conducted looking at strength, thermal expansion, setting expansion, and other related properties. It was soon apparent that very little was known about dimensional changes occurring in these products when they are subjected to the techniques used in prosthetic dentistry. A program was set up to determine the 
dimensional changes which occur when plaster and stone are subjected to the conditions found in dental practice. The methods used to observe length changes of gypsum after it has set have been rather crude and are not adaptable to observing the effect of various conditioning and processing techniques. Basically, three methods have been used to measure these changes, with each having its characteristic disadvantage. Those methods that depend on a micrometer coming in contact with the surface of a plaster or stone sample are subject to error on repeated measurements because of the ease with which the surface is abraded or worn away. The methods, which use index lines and a comparator microscope, present practical difficulties in alignment and in getting suitable lines on the sample. Methods for observing length changes by using a dial gauge in contact with a single specimen, which is not removed, restrict the number of specimens that can be measured conveniently. For this experiment the change in length of the specimen is determined by observing the difference in dimensions developed between the reference plane and the point. It has been found that by comparing the length of the specimen with gauge blocks, by use of an Electrolimit Comparator, it is possible to make rapid measurements accurate to the order of 0.0001 inch or better. The method that he describes provides a means of determining the dimensional changes occurring in gypsum products with great sensitivity. It allows the use of a greater variety of treatments and avoids the failings inherent in previous methods used for this purpose. ${ }^{10}$

Thiekle et. al. ${ }^{11}$ further developed a method for true coordinate three-dimensional measurement of stone specimens. The three dimensional measurement of locations on dental casts can be an indispensable tool in evaluating materials, die systems, and other dental devices. Instead of simply measuring relative distances, a true three-dimensional 
system can characterize the exact position and movement of components of a model and thus can define more exactly the fidelity of materials and techniques. In this study he describes a technique for analyzing casts in 3-dimensions that requires only a measuring microscope and a personal computer spreadsheet program. Through the use of a measuring microscope and a personal computer, the technique presented in this article provides meaningful and accurate 3-dimensional measurements of casts in true coordinates $(\mathrm{x}, \mathrm{y}, \mathrm{z})$. By fabricating the master cast with reference landmarks, leveling the casts before measurement, removing the cast between repeat measures, and mathematically rotating the data points, this technique places all the landmarks in a standardized reference plane that allows for the comparison of dimensional changes between different casts. ${ }^{11}$

Several studies have been performed specifically looking at methods of measuring stone expansion. Some of these studies even compare different forms of doing so. Winkler et $\mathrm{al}^{12}$ carried out a study comparing four methods for ascertaining the setting time of gypsum. The photomicrographically documented transformation from calcium sulfate hemihydrate crystals to an interdigitating mesh of dihydrate crystals was compared with setting expansion, $\mathrm{x}$-ray detected percentage of crystal structure, and Gillmore needle final set. Dimensional changes agreed most closely with the x-ray diffraction data that denoted the percentage of dihydrate crystal formation during setting. Final setting times, when ranked in order from shortest to longest, were Gillmore needle indentation, scanning electron microscopy, setting expansion, and x-ray diffraction. If the setting gypsum is disturbed in any way after the clinically relevant set before final set, the still developing microscopic structure of the gypsum may be adversely affected and 
result in problems such as weakened, easily abraded, or distorted casts. ${ }^{12}$ In 1992 Millstein ${ }^{13}$ conducted a study to evaluate the accuracy of casts made in Type IV dental stone. He used as his method making an impression of his test model. The impression was then cast in dental stone, and the differences between the stone cast and the model are compared using a precision-fitted template and a dial gauge. Cast distortion was determined by measuring the relative movement of a fixed template away from a fixed reference position. This movement occurred in a three-dimensional space and was found to vary both between and within the test groups. The measurement system used in this study enables a clinician to determine visually or quantitate numerically the effects of cast distortion frequently to determine their accuracy. ${ }^{13}$ A low-expansion die stone as defined in this study is one that expands by no more than $0.1 \%$, and is in accordance with the property requirements for setting expansion as determined by American Dental Association Specification No. 25 for Dental Gypsum products. A high-expansion die stone is one that exceeds this property requirement because it expands by more than $0.1 \% .^{2}$ Super Die, which is also a low expansion die stone, produced a greater degree of cast distortion than either Velmix or Silky Rock. In Japan, in 1979, Hosoda and Ohsawa $^{14}$ took an optical feeler measurement in order to investigate the dimensional accuracy of indirect stone models. A new procedure was employed for determining the fiducial height of measurement and examining the dimensional changes in detail at different heights of the specimens. This technique also has the advantage of hardly injuring the surfaces of the resultant stone models. ${ }^{14}$

There are further studies that have evaluated certain different properties of gypsum products. Probably most important in the researching of gypsum is studying different 
types of handling techniques and their influence on the resulting properties of the gypsum specimens. Lindquist et. al. ${ }^{15}$ looked at three different methods of preparing plaster mixes. These techniques were 1) spatulation by hand 2) spatulation by hand plus the auxiliary use of vacuum and 3) power driven mechanical spatulation. Also included were methods of adding plaster to the water, and the type of equipment used in hand technique. The power-driven mechanical spatulator used in this study produced the most consistent results. The main difference between vacuum and power-driven spatulation seems to be that vacuum does reduce the number of bubbles, although the few that remain are rather large. Mechanical spatulation does not eliminate as many voids but those that remain are broken down to a much smaller size. Water-plaster ratio and proper mixing procedure must be adhered to. Data in this study show the inferior properties present when the plaster technique is uncontrolled. ${ }^{15}$ Docking $^{16}$ looked at the processes of setting gypsum. He studied the course of precipitation of a setting gypsum system by taking aliquots at intervals and analyzing them to give a relationship between concentration and time, thus giving precipitation rates and other data. The more convenient method of tracing these data continuously by conductimetric means was used; this was based on the fact that the electrical resistance of the solution varies with the decreasing concentration of calcium and sulfate ions. He found that except for the effectiveness of those substances presenting a large area for nucleation and crystal growth, gypsum is the most potent precipitant. ${ }^{16}$ In 1966 Earnshaw ${ }^{17}$ looked at how tensile and compressive strength is altered by the handling of plaster and die stone. His results indicated that variations in water/powder ratio affects tensile strength less than compressive strength. For this reason there was not a constant relation between tensile 
and compressive strengths, for all the gypsum specimens tested in this investigation. Materials mixed in the highest W/P ratios had tensile strengths as high as 25 per cent of their compressive strengths. Materials mixed in the lowest w/p ratios had tensile strengths which were less than 10 percent of their compressive strengths. ${ }^{17}$ In studying any characteristics of gypsum products it is important to know how to obtain ideal characteristics. In the practical manipulation of laboratory plaster and stone it is customary to obtain optimal strength properties in the set mass by preparing a thick mix, resulting from a low w/p ratio, and to use a vibrator to improve the fluidity of the mix when it is poured. Earnshaw ${ }^{17}$ looked at these necessary characteristics and how to obtain them. He discovered in his study that there is a substantially linear relationship between $\mathrm{W} / \mathrm{P}$ ratio and consistency, expressed as a square of the overall length of the slump, would seem to justify using this, rather than the length itself, as a basis for comparison of the consistency of mixes of different materials or different mixes of a given material. ${ }^{18}$ It has also been investigated that additives can improve the mechanical properties of gypsum products. Sanad et. al. ${ }^{19}$ researched that by use of a combination of calcium oxide and gum arabic additives, it was possible to produce gypsum products with greater abrasion resistance and compressive strength as well as tensile strength. It was also possible to reduce w/p ratios so that denser gypsum cast could be used leading to significant improvement of mechanical properties. ${ }^{19}$

In this study that will be conducted, air humidity will be a factor in the outcome of results on the gypsum specimens. Therefore, it is finally important to look at past findings on the effects of humidity on the expansion and mechanical properties of dental stone. Brukl et. al. ${ }^{7}$ found expansion decreased as a function of water preparation in the 
order slurry suspensions, unadulterated water, and supernate solutions. For the type III dental stone that he tested, the expansions ranged between $0.12 \%$ and $0.139 \%$ and thus fell below the specification limit of $0.2 \%$. When grouped by water type, distilled, deionized, and hard water yielded significantly greater expansions when water saturated with gypsum was used than when unadulterated or slurry water was used. Depending on the bicarbonate content and $\mathrm{pH}$ variation resulting from dissolution of carbon dioxide from the air, distilled and deionized waters may yield variable setting times. Slurry water is an effective setting accelerator for both modified and additive-free gypsum products. In contrast, a gypsum-saturated supernate solution is not an accelerator and may act as a weak retarder. ${ }^{7}$ Buchanan and Worner ${ }^{20}$ looked at samples of dental plasters after mixing which were exposed to atmospheres of $15 \%$ and $100 \%$ relative humidity for prolonged periods and tested at regular intervals. Both analytical and microscopic evidence showed that the plasters absorbed water from the moist atmosphere and underwent hydration to $\mathrm{CaSO}_{4} 2 \mathrm{H}_{2} \mathrm{O}$. The rate of absorption of moisture at any particular humidity appears to depend mainly on the quantity of dehydrate already present in the plaster. The setting rate increases continuously on exposure, ultimately making the plaster unusable. The fast setting plasters were found to contain an abnormally high percentage of gypsum ranging from ranging from $1-10 \%{ }^{20}$ Humidity has an evident effect on the calcium sulfate hemihydrate phase of gypsum. Dental stone can be subjected to levels of humidity during storage. This is important to the study at hand because it will measure expansion during the storage time of the gypsum specimens. This was looked at by Torrance and Darvell $^{21}$ in 1990. They found that hemihydrate powders exposed to water vapor converted to dihydrate at a rate and to an extent dependent on the water vapor pressure, 
but with apparent critical pressure of $2.3 \mathrm{kPa}$ at $23^{0} \mathrm{C}$. The use of relative humidity to establish a safe range condition for hemihydrate powders is found be overly simplistic, even if conservative at low temperature. Earlier recommendations are founded very little data, much of which is of dubious value. ${ }^{21}$

A very important factor in the handling of gypsum products in dentistry is compatibility with the materials used when impressing. To reproduce a clinical situation, one must look at how the expansion of dental gypsum is affected by its compatibility with different types of impression materials. In 1987 Gerrow and Schneider ${ }^{22}$ looked at a group of different elastomeric impression materials and their respective compatibilities with type IV dental stone. Gerrow ${ }^{22}$ created 48 systems arranged so that each system contained a different impression material, dental stone and liquid media combination. Five test dies of each system (240 total) were prepared in a random order with the use of the ADA apparatus for detail reproduction compatibility, and dimensional stability. All materials and instruments were in the testing room for at least 24 hours prior to their use. Room temperature and humidity were controlled between $21^{\circ} \mathrm{C}$ and $23^{\circ} \mathrm{C}$ and between $30 \%$ and $40 \%$, respectively. Prior to each use, surface debris was removed from the polished surface of the test block with methyl alcohol on a cotton gauze sponge. In Gerrow's findings, all systems except those containing Permlastic impression material with Vel-mix, Silky Rock, or Glastone 2000 dental stone met the ADA criteria. Systems containing Rubberloid impression material did meet the criteria in ADA specification No. 11 (dental agar) but did not meet the criteria in specification No. 19 (elastomeric). These results also indicated that Permlastic and Rubberloid impression materials are not able to reproduce the same detail on a test cast as Reprosil or Impregum impression materials. 
Permlastic and Rubberloid materials did reproduce detail on the impression surface but failed to transfer the detail to the cast. The results obtained with Rubberloid impression materials are in accordance with the different requirements for compatibility in ADA specification No. 11 and specification No. 19. The use of a lower water/powder ratio with the gypsum hardeners did not affect the compatibility of the impression materials and dental stones. This study and the ADA certification program tested the compatibility of materials solely on the ability to reproduce surface detail. ${ }^{22}$ Later in 1988 Schelb et. al. ${ }^{23}$ tested compatibility of type IV dental stones with polyether impression materials. ADA specification No. 19 requires that a $20 \mu \mathrm{m}$ line in the surface of the impression material be reproduced in an unmodified gypsum cast in order for the materials to be considered compatible. Three polyether impression materials and 14 modified type IV dental stones for a possible 42 combinations were selected for this study. Four samples of each combination were produced for a total of 168 specimens. The base and catalyst of each impression material were weighed and mixed according to manufacturer's recommendations. A circular metal plate $(\mathrm{CC})$ was placed inside a brass ring $(\mathrm{BB})$ and the impression material was loaded into the ring. A $20 \mu \mathrm{m}$ line was scribed into four $2 \mathrm{X}$ 2 inch glass plates. The ability to reproduce a $20 \mu \mathrm{m}$ wide line can be used to determine compatibility between polyether impression materials and dental stones. Permadyne with Supercal materials reproduced the line $100 \%$ of the time. The results of this studied demonstrated a need for manufacturers to identify dental stones that are compatible with their impression materials. ${ }^{23}$

A high expansion stone has been used for improving the adaptation of dentures. Although the method is based on the idea to compensate for the processing shrinkage of 
the denture base resin with the high expansion stone, there are few studies on the expansion behavior of stones in an impression. In 2000 Teraoka $^{24}$ studied the dimensional changes and pressure of dental stones set in silicone rubber impressions. Impressions of a master model that represents the alveolar ridge were taken using a silicone impression material and the dimensional changes in the stone casts were measured in different directions ( $\mathrm{x}, \mathrm{y}$, and $\mathrm{z}$ axes). Two types of impression tray were used, one with an open surface and the other with a closed surface. In order to evaluate the setting expansion of the stones and the pressure against the impression, stones were poured in other impressions that were taken from a cubic master model. The thickness of the impression was set at $2 \mathrm{~mm}$. A statistical analysis showed that there were significant differences in the dimensional change in the vertical direction (z-axis) and horizontal directions ( $\mathrm{x}$ and $\mathrm{y}$-axes) of any stone casts set in the open tray (an expansion measuring trough without a cover). However, there were no significant differences in the dimensional changes in any direction of each stone cast set in the closed dimensional changes in any direction of each stone cast set in the closed tray (an expansion measuring trough with a cover). In his experiment he measured three brands of dental stone (Himount, Gypstone, and Gypstone GH) and found the expansion percentages respectively for open and closed trays to be $.06 \%, .23 \%$, and $.407 \%$. The ultimate finding of this study is that the impression tray influences the setting expansion of stones. ${ }^{24}$

In the this study ADA Specification No. $25^{2}$ and the manufacturers recommendations were followed. Specification No. $25^{2}$ for setting expansion states that the change in length on setting shall be determined by observing the movement of ruled markers placed approximately $30 \mathrm{~cm}$ apart on a specimen in a 90 degree $\mathrm{V}$-shaped trough. It further 
states that observations were to be made with a micrometer microscope comparator or by the use of equipment of equal accuracy. The V-shaped trough, into which the specimen is poured, shall be lined with rubber dam. The initial reading was to be made one minute before the time of setting. The final reading was to be made two hours after the start of mix. A standard mix composed of $100 \mathrm{~g}$ of the powder and the proper amount of water shall be made and placed in the prepared trough. The entire mix shall be used and the overall length of the poured mass shall not exceed $36 \mathrm{~cm}$. The average of two tests shall be reported to the nearest 0.01 percent. The revised American dental association specification No. $25^{2}$ for Dental gypsum products has been approved by the Council on Dental Materials, Instruments and equipment of the American Dental Association. ${ }^{2}$ The ADA specifications for dental gypsum are provided in Table $1 .^{2}$ The manufacturer specifications and recommendations for materials handling for the stone being studied are provided in Table 2 . 
Table 1. ADA Specification 25 for Dental Gypsum Products

\section{AMERICAN DENTAL ASSOCLATION SPECIFICATION No.25 FOR DENTAL GYPSUM PRODUCTS}

\begin{tabular}{|c|c|c|c|c|c|c|c|c|}
\hline \multirow[b]{2}{*}{ Iyp: } & \multirow{2}{*}{$\begin{array}{l}\text { Satting } \\
\text { tide. } \\
\text { ninutes }\end{array}$} & \multicolumn{2}{|c|}{ 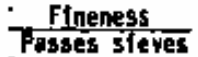 } & \multicolumn{2}{|c|}{$\begin{array}{c}\text { Settling } \\
\text { expynstan } \\
\text { at 2 hre. }\end{array}$} & \multicolumn{2}{|c|}{$\begin{array}{l}\text { toprefslve } \\
\text { strength ot } \\
\text { i hour }\end{array}$} & \multirow{2}{*}{ 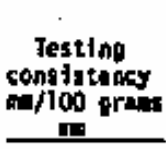 } \\
\hline & & -1 & 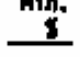 & . & $\underline{1}$ & $m / t^{2}$ & $\mathrm{~kg} / \mathrm{cos}^{2}$ & \\
\hline I, oloster. |npression & $4 \pm 1$ & og & 85 & 0.00 & 0.15 & 4.0 .7 .0 & $40 \pm 20$ & -- \\
\hline 1I, plaster, rodel & $12 \pm 4$ & ss & 50 & 0.00 & 0.30 & Q.8 gin. & go atn. & $30+2^{*}$ \\
\hline 11I, dental stons & $12 \pm 4$ & 9 & 90 & $0 . \infty$ & 0.20 & 20.6 aln. & $210 \mathrm{mtn}$. & $30 \times 2^{* 2}$ \\
\hline $\begin{array}{l}\text { 1V, dentel stonk, } \\
\text { high streng th }\end{array}$ & $32 \pm 4$ & 90 & 50 & 6.00 & 0.10 & 34.3 aln. & 350 mis. & $30 \div 2^{2 *}$ \\
\hline
\end{tabular}

Table 2. Manufacturers Specifications for Improved Dental Stones

$$
\text { Water/ Mixing Working Setting Compressive } 2 \mathrm{hr} \text {. }
$$

PRODUCT 100 gm Time [min] Time [min] Time [min] Strength [psi] Expansion \%

\begin{tabular}{|l|l|l|l|l|l|l|l|l|l|l|l|l|l|l|l|} 
Hard Rock & 21 & $20-30$ & $6-8$ & 15 & 0.28 \\
Prima Rock & 20 & $20-30$ & $6-8$ & 12 & 8000 & 0.13 \\
Silky Rock & 23 & $20-30$ & $3-6$ & 10 & 6000 & 0.09
\end{tabular}




\section{CHAPTER III: MATERIALS AND METHODS}

In this study on linear expansion of dental stone specific materials and methodology were used. The samples came from three different types of Type IV and Type V dental stones. From each of these three brands of stone five specimen were blocks made. The three specific brands of dental stone tested were Hard Rock, Prima Rock, Silky rock.

The specific design of this research study involved a comparison of the linear setting expansion of three commonly used ADA Type IV and V dental stones at eight time intervals. Five specimens were taken of each of the dental stones being studied and average setting expansions recorded at the specific intervals was used to construct a mean setting expansion. The setting expansion on these three type IV dental stones were measured with the SAM Electronic Measuring Device (EMI) 100. This expansionmeasuring device has a mechanical dial gauge giving expansion readings in millimeters (accurate to $.01 \mathrm{~mm}$ ), which were visually recorded by the researcher. The mean setting expansions were then compared between the different brands of dental improved stones. Each of the intervals of setting expansion data was also compared with its own base measurement for that specific stone to see how much more expansion occurs after the supposed final set. The data collected with this instrumentation was statistically analyzed using the ANOVA and Tukey Multiple Range Test.

Dental Stone was mixed under vacuum according to the manufacturer's instructions with a mechanical vacuum mixer at 1425 RPM mixing for 25 seconds. The vacuum mixer creates a vacuum inside the mixing bowl of $90 \mathrm{kPa}$, while the speed of the spinning blade in the mixing bowl was $1425 \mathrm{rpm}$. The water powder ratio was controlled using 
prepackaged stone and a $10 \mathrm{ml}$ syringe using distilled water. Proceeding are water to powder ratios recommended by the manufacturer that were followed in this experiment: Hard Rock: $21 \mathrm{~mL}$ water/100g powder Prima Rock: $20 \mathrm{~mL}$ water/100g powder Silky Rock: $23 \mathrm{~mL}$ water/100g powder After mixing, the stone specimens were vibrated into a measuring trough in the SAM EMI 100 lined with a thin sheet of rubber dam. The SAM EMI 100 is specially designed to determine the setting expansion of dental materials. The dial gauge, attached to the EMI, is calibrated to $0.01 \mathrm{~mm}$ increments with possible measurement values of less than $0.005 \mathrm{~mm}$. For all expansion measurements the EMI trough was lined with a low friction material to prevent the adhesion of the stones to the EMI. The ADA recommends that this material be a thin sheet of rubber dam $(0.1-0.2 \mathrm{~mm}$ thick), lubricated with a thin layer of talcum powder cornstarch free. This allows a small space of freedom inside the measuring trough for the stone to expand and gives an output measurement to the dial gauge. The expansion was monitored at various intervals to assess \% expansion and stability. Measurements were recorded at

1min before $\quad 2 \mathrm{hrs} \quad 24 \mathrm{hrs} \quad 48 \mathrm{hrs} \quad 72 \mathrm{hrs}$ initial set

$96 \mathrm{hrs} \quad 120 \mathrm{hrs} \quad 168 \mathrm{hrs}$

Each of the three stones were mixed and measured 5 times for consistency of results.

Data collection began at 1 minute before the initial set and stopped at 168 hours. This data collection was read by the experimenter and recorded manually in a data log. The percentage linear setting expansion data was subjected to two different kinds of statistical 
analysis. First was the two-way ANOVA test. Analysis of variance (ANOVA) is a powerful method of analyzing differences among a number of groups. ${ }^{5}$ The second statistical analysis used was the Tukey Multiple Range test (HSD-honestly significant difference test). This analysis was used to test the hypothesis that all possible pairs of means were equal. The HSD value was then computed and all differences were compared to it. Those pairs whose differences exceeded the HSD were considered significantly different. ${ }^{5}$ 


\section{CHAPTER IV: RESULTS AND DISCUSSION}

\section{RESULTS}

Linear expansion data for the 3 tested dental stones at the 8 time intervals are provided in Tables 3, 4, 5. Figure 1 illustrates a plot of the linear expansion data over 168 hours for each of the dental stones tested. All stones showed expansion over time. Of the three stones tested Silky Rock and Hard Rock plateaued at 48 hours while Prima Rock continued undergoing linear expansion until 96 hours $(\mathrm{P}<.0001)$. Analysis was carried out using analysis of variance for a repeated measures design. Differences between times with a stone were assessed using Tukey's HSD test. Hard Rock at 168 hours recorded the highest mean setting expansion values (.28\% standard error .0076) Silky Rock recorded the lowest (.14\% standard error .0076). All stones had higher linear expansion values at 168 hours than at 2 hours. Expansion was essentially completed for all specimens at 48 hours except for those fabricated from Prima Rock which remained linearly stable at 72 hours. 
Table 3. Raw Data for Silky Rock

\section{Dental Stone Expansion \%}

\begin{tabular}{|l|c|c|c|c|c|c|c|c|}
\hline DENTAL STONE & $\begin{array}{c}1 \mathrm{~min} . \\
\text { before set }\end{array}$ & $\begin{array}{c}2 \mathrm{hrs} \\
\text { after mix }\end{array}$ & $24 \mathrm{hrs}$. & $48 \mathrm{hrs}$ & $72 \mathrm{hrs}$. & $96 \mathrm{hrs}$. & $120 \mathrm{hrs}$. & $168 \mathrm{hrs}$. \\
\hline
\end{tabular}

\begin{tabular}{r|r|r|r|r|r|r|r|r|}
\cline { 2 - 8 } Silky Rock \#1 & 0.04 & 0.11 & 0.14 & 0.14 & 0.15 & 0.15 & 0.15 & 0.15 \\
\cline { 2 - 9 } Room Temp F & 73.2 & 70.7 & 70.5 & 66.9 & 63.3 & 64 & 64.9 & 67.3 \\
\cline { 2 - 10 } Humidity \% & 33 & 36 & 48 & 64 & 52 & 60 & 66 & 42 \\
\cline { 2 - 8 }
\end{tabular}

\begin{tabular}{r|r|r|r|r|r|r|r|r|} 
Silky Rock \#2 \\
\cline { 2 - 9 } Room Temp F \\
\cline { 2 - 9 } \\
\cline { 2 - 9 } & 0.04 & 0.11 & 0.13 & 0.14 & 0.14 & 0.14 & 0.14 & 0.14 \\
\cline { 2 - 9 } & 72.3 & 69.4 & 72.3 & 68.2 & 65.3 & 66.9 & 66.4 & 57 \\
\hline
\end{tabular}

Silky Rock \#3

\begin{tabular}{|r|r|r|r|r|r|r|r|}
\hline 0.05 & 0.11 & 0.13 & 0.14 & 0.14 & 0.16 & 0.16 & 0.16 \\
\hline 66 & 65.5 & 64 & 65 & 63.5 & 65 & 64 & 67.8 \\
\hline 31 & 31 & 30 & 32 & 30 & 28 & 31 & 34 \\
\hline
\end{tabular}

\section{Silky Rock \#4}

Room Temp $F$ Humidity \%

\begin{tabular}{|r|r|r|}
\hline 0.05 & 0.11 & 0.1 \\
\hline 66 & 65 & 65 \\
\hline 39 & 39 & 35 \\
\hline
\end{tabular}

\begin{tabular}{r|r|r|r|r|r|}
\hline 0.12 & 0.14 & 0.14 & 0.14 & 0.14 & 0.14 \\
\hline 65 & 62 & 64 & 63.5 & 64 & 65 \\
\hline 35 & 35 & 38 & 36 & 37 & 36 \\
\hline
\end{tabular}

Silky Rock \#5

Room Temp F

Humidity \%

\begin{tabular}{|r|r|r|}
\hline 0.04 & 0.11 & 0.13 \\
\hline 66.4 & 66 & 65 \\
\hline 35 & 35 & 33 \\
\hline
\end{tabular}

\begin{tabular}{r|r|r|r|r|r|}
0.13 & 0.15 & 0.15 & 0.15 & 0.15 & 0.15 \\
\hline 65 & 65.5 & 66 & 65.5 & 65 & 65.5 \\
\hline 33 & 30 & 32 & 32 & 33 & 29 \\
\hline
\end{tabular}


Table 4. Raw Data Prima Rock

\section{Dental Stone Expansion \%}

\begin{tabular}{|c|c|c|c|c|c|c|c|c|}
\hline DENTAL STONE & $\begin{array}{c}1 \mathrm{~min} . \\
\text { before set }\end{array}$ & $\begin{array}{c}2 \mathrm{hrs} \\
\text { after mix }\end{array}$ & $24 \mathrm{hrs}$. & $48 \mathrm{hrs}$ & $72 \mathrm{hrs}$. & $96 \mathrm{hrs}$. & $120 \mathrm{hrs}$. & $168 \mathrm{hrs}$. \\
\hline \multirow{3}{*}{$\begin{array}{r}\text { Prima Rock \#1 } \\
\text { Room Temp F } \\
\text { Humidity } \%\end{array}$} & 0.07 & 0.16 & 0.18 & 0.19 & 0.2 & 0.2 & 0.21 & 0.22 \\
\hline & 73.2 & 70.7 & 70.5 & 66.9 & 63.3 & 64 & 65.1 & 67.3 \\
\hline & 32 & 36 & 49 & 64 & 52 & 60 & 66 & 42 \\
\hline \multirow{3}{*}{$\begin{array}{r}\text { Prima Rock \#2 } \\
\text { Room Temp F } \\
\text { Humidity \% }\end{array}$} & 0.05 & 0.15 & 0.17 & 0.18 & 0.18 & 0.19 & 0.19 & 0.19 \\
\hline & 72.7 & 69.4 & 72.3 & 68.2 & 65.3 & 66.9 & 66.4 & 67 \\
\hline & 36 & 34 & 41 & 37 & 42 & 54 & 59 & 52 \\
\hline \multirow{3}{*}{$\begin{array}{r}\text { Prima Rock \#3 } \\
\text { Room Temp F } \\
\text { Humidity \% }\end{array}$} & 0.06 & 0.17 & 0.18 & 0.19 & 0.27 & 0.27 & 0.28 & 0.28 \\
\hline & 66 & 65.5 & 64 & 65 & 63.5 & 65 & 64 & 67.8 \\
\hline & 31 & 31 & 30 & 32 & 30 & 28 & 31 & 34 \\
\hline \multirow{3}{*}{$\begin{array}{r}\text { Prima Rock \#4 } \\
\text { Room Temp F } \\
\text { Humidity \% }\end{array}$} & 0.07 & 0.16 & 0.17 & 0.18 & 0.19 & 0.19 & 0.2 & 0.2 \\
\hline & 66 & 65 & 65 & 62 & 64 & 63.5 & 64 & 65 \\
\hline & 39 & 39 & 35 & 35 & 38 & 36 & 37 & 36 \\
\hline \multirow{3}{*}{$\begin{array}{r}\text { Prima Rock \#5 } \\
\text { Room Temp F } \\
\text { Humidity \% }\end{array}$} & 0.06 & 0.16 & 0.17 & \begin{tabular}{l|l|}
0.19 \\
\end{tabular} & 0.19 & 0.19 & 0.21 & 0.21 \\
\hline & 66.4 & 66 & 65 & 65.5 & 66 & 65.5 & 65 & 65.5 \\
\hline & 35 & 35 & 33 & 30 & 32 & 32 & 33 & 29 \\
\hline
\end{tabular}


Table 5. Raw Data for Hard Rock

\section{Dental Stone Expansion \%}

\begin{tabular}{|c|c|c|c|c|c|c|c|c|}
\hline DENTAL STONE & $\begin{array}{c}1 \mathrm{~min} . \\
\text { before set } \\
\end{array}$ & $\begin{array}{c}2 \mathrm{hrs} \\
\text { after mix }\end{array}$ & 24 hrs. & $48 \mathrm{hrs}$ & 72 hrs. & $96 \mathrm{hrs}$. & $120 \mathrm{hrs}$. & $168 \mathrm{hrs}$. \\
\hline \multirow{3}{*}{$\begin{array}{l}\text { Hard Rock \#1 } \\
\text { Room Temp F } \\
\text { Humidity } \%\end{array}$} & 0.04 & 0.25 & 0.29 & 0.29 & 0.3 & 0.3 & 0.3 & 0.3 \\
\hline & 73.4 & 70.7 & 70.5 & 66.9 & 63.3 & 64 & 65.1 & 67.3 \\
\hline & 32 & 36 & 49 & 66 & 52 & 60 & 66 & 42 \\
\hline \multirow{3}{*}{$\begin{array}{l}\text { Hard Rock \#2 } \\
\text { Room Temp F } \\
\text { Humidity } \%\end{array}$} & 0.03 & 0.25 & 0.28 & 0.28 & 0.28 & 0.28 & 0.28 & 0.28 \\
\hline & 73.2 & 69.4 & 72.3 & 68.2 & 65.3 & 66.9 & 66.4 & 67 \\
\hline & 36 & 34 & 41 & 38 & 43 & 59 & 59 & 52 \\
\hline \multirow{3}{*}{$\begin{array}{l}\text { Hard Rock \#3 } \\
\text { Room Temp F } \\
\text { Humidity \% }\end{array}$} & 0.03 & 0.23 & 0.26 & 0.28 & 0.3 & 0.3 & 0.3 & 0.3 \\
\hline & 66 & 65.5 & 64 & 65 & 63.5 & 65 & 64 & 67.8 \\
\hline & 31 & 31 & 30 & 32 & 30 & 28 & 31 & 34 \\
\hline \multirow{3}{*}{$\begin{array}{r}\text { Hard Rock \#4 } \\
\text { Room Temp F } \\
\text { Humidity \% }\end{array}$} & 0.04 & 0.24 & 0.27 & 0.28 & 0.3 & 0.3 & 0.3 & 0.3 \\
\hline & 66 & 65 & 65 & 62 & 64 & 63.5 & 64 & 65 \\
\hline & 39 & 39 & 35 & 35 & 38 & 36 & 37 & 36 \\
\hline \multirow{3}{*}{$\begin{array}{r}\text { Hard Rock \#5 } \\
\text { Room Temp F } \\
\text { Humidity } \%\end{array}$} & 0.04 & 0.24 & 0.27 & 0.28 & 0.3 & 0.3 & 0.3 & 0.3 \\
\hline & 66.4 & 66 & 65 & 65.5 & 66 & 65.5 & 65 & 65.5 \\
\hline & 35 & 35 & 33 & 30 & 32 & 32 & 33 & 29 \\
\hline
\end{tabular}


Figure 1. Comparison of Mean Linear Expansion

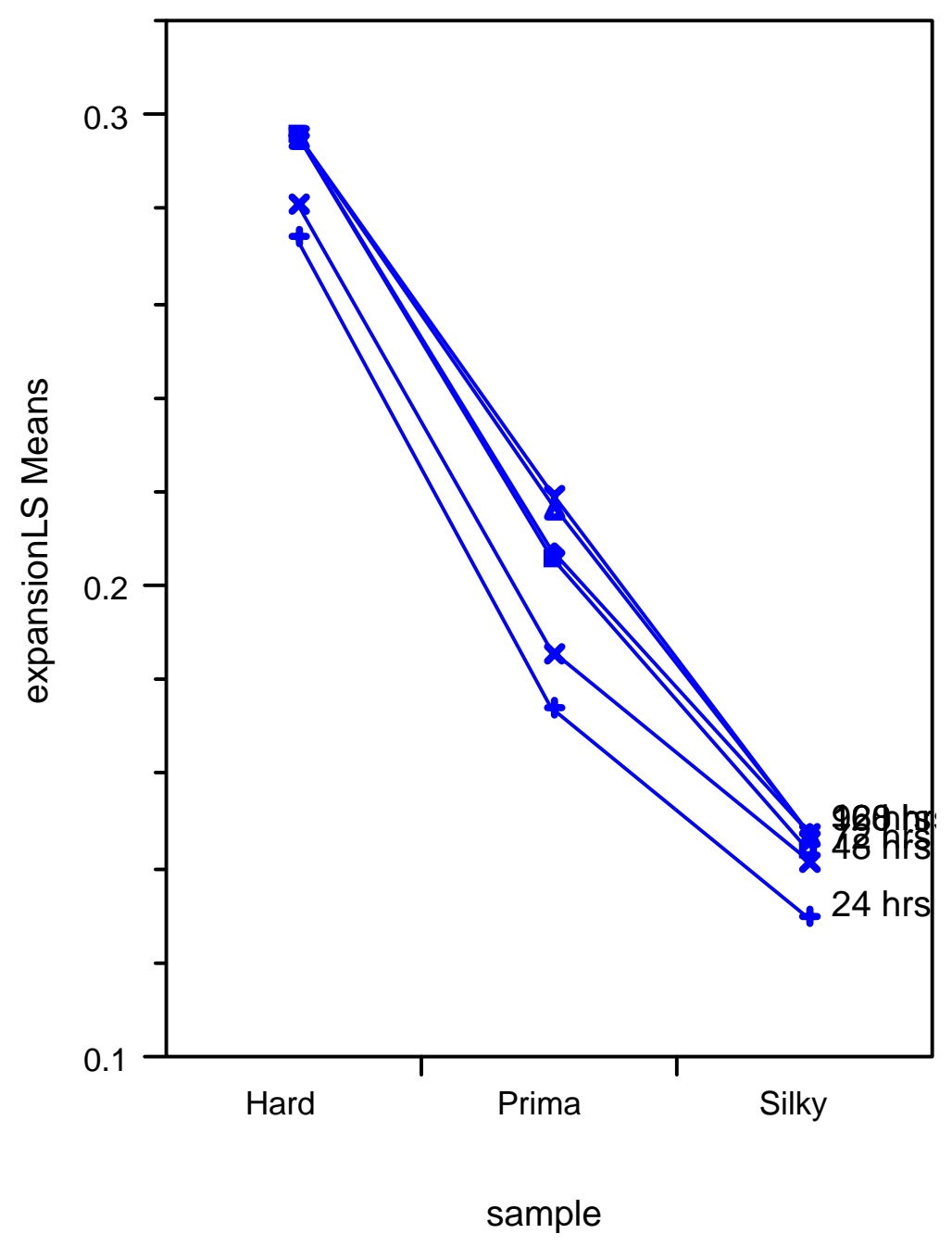




\section{DISCUSSION}

Prosthetic restorations can be fabricated satisfactorily if the working cast used in the indirect fabrication techniques meet certain requirements. In such cases long term dimensional accuracy of the dental stones used is of the utmost importance. The results of this study illustrated that among the die stones there were differences in the linear expansion beyond 2 hours continuing until 168 hours. The linear expansion test results obtained should help determine the limitations of dental stones used and make it possible to more intelligently choose the best materials, or combinations of materials and stones, for a specific use. The only ADA type V dental stone tested (Hard Rock) exhibited a higher 168-hour mean expansion values than the two ADA type IV dental stones tested (Silky Rock and Prima Rock). ADA Specification 25 indicates that type V

stones should not exceed $.30 \%$ linear setting expansion. ${ }^{2}$ The results of this study suggest that Hard Rock (.28\%) would meet the specification even at 168 hours. The two hour mean setting expansion for all stones tested suggest they would all meet the ADA guidelines for linear setting expansion at 2 hours.

Assuming that a clinician or laboratory technician would interpret the setting expansion value stated by the manufacturer as that product's maximum setting expansion is reasonable. Hard Rock illustrated the highest total mean linear setting expansion at 168 hours. Silky Rock exhibited the least setting expansion after 2 hours. The linear expansion for both Hard Rock and Silky Rock was essentially completed by 48 hours. Mean linear expansion values were not comparable at 2 hours to those suggested by the manufacturer. Setting expansion of the Type IV improved dental stones ranged from $.11 \%$ to $.16 \%$. Silky Rock proved to have the lowest expansion value, whereas Prima 
Rock had the highest expansion for the two type IV improved dental stones tested. Prima Rock (.16\%) and Silky Rock (.11\%) both exhibited greater mean linear expansion values than that suggested by the manufacturer (.13\% and .09\% respectively). Hard Rock (.24\%), on the other hand, exhibited less mean linear expansion value than that suggested by the manufacturer $(.28 \%)$. However, the difference in all three stones would more than likely not be clinically relevant.

The unique and precise requirements of Prosthodontics have led to strict criteria regarding master cast accuracy and dimensional stability as well as the clinical outcome. The absence of a proper marginal fit and seal or of precision of fit in an implant prosthesis usually manifests as a clinical deficiency. The significance of accurate fit and seal for removable, fixed, as well as implant prosthodontics is well known. Prostheses should fit as accurately as possible to limit the amount of exposed luting media, and micromotion, as well as providing intimate fit and adequate peripheral seals with prosthetic retention and stability. The quality of restoration fit could be enhanced through use of the most desirable fabrication technique for the cast or die and selection of a stone that exhibits long-term stability and expansion. When the indirect technique is used, improved dental stones selection depends on analysis of the properties believed to be the most pertinent for the specific use of the master cast. According to the results of the present study, a dimensional factor that can be taken into account is the linear expansion of the stone being used beyond the two hour expansion value given by the manufacturer. Most prosthesis are not fabricated on the model within two hours of the fabrication of the master cast. The delayed linear expansion discovered in this study may not have a resulting clinical significance but it is good for the operator as well as the 
prosthetic technician to be aware of the fact that such a dimensional change is occurring over time.

Heshmati et $\mathrm{al}^{25}$ investigated the continued linear expansion of 6 ADA Type IV and V dental stones up to 120 hours. The stones studied were different than those studied in the present study. All stones tested exhibited continued linear expansion with all values greater at 120 hours than at 2 hours. Expansion was complete at 96 hours for all stones except Resin Rock (Whip Mix Corporation, Lexington, KY). This differs from the stones investigated in our study which did not expand beyond 48 hours (Silky Rock and Hard Rock) and 96 hours (Prima Rock). Both of these studies showed similar results in that both exhibited delayed linear expansion of Type IV and V dental stones beyond the two hour expansion.

Within the parameters of this experiment, all of the dental stones tested exhibited linear setting expansion beyond two hours while setting under typical prosthetic laboratory conditions. The amount of expansion varied significantly among materials. The experimental conditions were not controlled will the delayed linear expansion of each material took place. This was done on purpose in order to replicate typical clinical conditions. Dimensional change in the master cast materials can be influenced by many factors not covered in the current experiment. These can include impression materials, techniques, delays before pouring of final impressions, and handling of the master cast improved dental stones. However, this study does show that time is another factor influencing the dimensional properties of Type IV and V dental stones used commonly in treatment in Prosthodontics. 


\section{SUMMARY AND CONCLUSIONS SUMMARY}

CHAPTER V:

Dimensional stability is on of the most important factors in choosing dental materials necessary for the indirect technique of fabricating dental prostheses. In traditional crown and bridge prosthodontics, as well as removable prosthodontics, linear expansion of dental stones has always been a key factor in the fit and long term success of the

prostheses fabricated on working casts. ADA specification $25^{26}$ measures linear expansion of dental Type IV and V stones at 2 hours but does not account for any sort of continuing linear expansion beyond two hours.

Two type IV and one type V dental stones were measured for linear expansion beyond two hours up to 168 hours under common prosthetic laboratory conditions

All of the improved dental stones tested exhibited delayed linear expansion beyond 2 hours. Silky Rock and Hard Rock showed stability at the 48 hour mark, whereas Prima Rock did not plateau in delayed linear expansion until 96 hours. 


\section{CONCLUSIONS}

For acceptable restorations to be produced, the cast or die used in the indirect casting technique must be dimensionally accurate and stable, and they should exhibit accuracy over extended periods of time. ${ }^{3}$ The results of this study illustrated that among the Type IV and V dental stones tested, no single material was completely stable beyond its 2 hour set. However, Silky Rock and Hard Rock did exhibit greater stability than Prima Rock through 168 hours of analysis. Most often clinicians and laboratory technicians will trust the maximum expansion of improved dental stones to be that value stated by the manufacturer which is measured at two hours from the beginning of the mix. Silky Rock and Hard Rock were stable at 72 hours but Prima Rock exhibited continued expansion. Greater total expansion values were recorded at 168 hours for the Type V (Hard Rock) stones than for a type IV (Silky Rock and Prima Rock) dental stones. 


\section{RECOMMENDATIONS}

When handling ADA Type IV and V stones, the clinician and laboratory technician should pay attention to manufacturer specifications but understand that they are only up to two hours and may not portray the actual setting expansion of the stone over extended time. Because fabrication of restorations in commercial dental laboratories takes from one to three weeks, it is recommended that all type IV and V dental stones be tested for up to 168 hours for total expansion and dimensional stability. ADA Specification \#25 should be revised to require this extended data be provided to clinicians and laboratory technicians. 


\section{LITERATURE CITED}

Craig RG: RESTORATIVE DENTAL MATERIALS. Mosby St. Louis 1997. ANSI/ADA Specification No. 25 - 1980. Approved October 27, 1980.

Glossary of Prosthodontic Terms. Seventh Edition, The Academy of Prosthodontics. Journal of Prosthetic Dentistry. January 1999.

Anusavice KJ: PHILLIP'S SCIENCE OF DENTAL MATERIALS. $10^{\text {th }}$ EDITION. WB Saunder's Company 1996.

Kuzma JW: Basic Statistics for the Health Sciences. Mayfield Mountainview, Ca 1998.

Mahler DB: Plasters of Paris and stone materials. International Journal of Dentistry 5:241-253, 1955.

Brukl CE, McConnell BS, Norling BK, and Collard SM: Influence of gauging water composition on dental stone expansion and setting time. Journal of Prosthetic Dentistry 51:218-223, 1984.

Lautenschlager EP, Corbin F: Investigation of the expansion of dental stone. Journal of Dental Research 48:206-210, 1969.

Combe EC, Smith DC: Some properties of gypsum plasters. British Dental Journal 117:237-245, 1964.

Sweeney WT, Taylor DF: Dimensional changes in dental stone and plaster. Journal of Dental Research 29:749-755, 1950.

Thiekle S, Serrano JG, Lepe X: A method for true coordinate three-dimensional measurement of casts using a measuring microscope. Journal of Prosthetic Dentistry 80:506-510, 1998.

Winkler MW, Monaghan P, Gilbert JL, Lautenschlager EP: Comparison of four techniques for monitoring the setting kinetics of gypsum. Journal of Prosthetic Dentistry 79:532-536, 1998.

Millstein RL: Determining the accuracy of gypsum casts made from type IV dental stone. Journal of Oral Rehabilitation 19:239-243, 1992.

Hosoda H, Ohsawa M: Evaluating dimensional accuracy of stone models. Journal of Dental Research 58:1352-1357, 1979.

Lindquist JT, Brennan RE, Phillips RW: Influence of mixing techniques on some physical properties of plaster. Journal of Prosthetic Dentistry 3:274-285, 1953. 
Docking AR: Some gypsum precipitates. Australian Dental Journal 10:428-430, 1965.

Earnshaw R, Smith DC: The tensile and compressive strength of plaster and stone. Australian Dental Journal 11:415-422, 1966.

Earnshaw R: The consistency of gypsum products. Australian Dental Journal 18:33-37, 1973.

Sanad MEE, Combe EC, Grant AA: The use of additives to improve the mechanical properties of gypsum products. Journal of Dental Research 61:808-810, 1982.

Buchanan AS, Worner HK: Changes in the composition and setting characteristics of plaster of Paris on exposure to high humidity atmospheres. Journal of Dental Research 24:65-75, 1945.

Torrance A, Darvell BW: Effect of humidity on calcium sulfate hemihydrate. Australian Dental Journal 35:230-235, 1990.

Gerrow JD, Schneider RL: A comparison of the compatibility of elastomeric impression materials, type IV dental stones, and liquid media. Journal of Prosthetic Dentistry 57:292-297, 1987.

Schelb E, Cavazos E, Kaiser DA: Compatibility of typeIV dental stones with polyether impression materials. Journal of Prosthetic Dentistry 60:540-542, 1988.

Teraoka F, Takahashi J: Dimensional changes and pressure of dental stones set in silicone rubber impressions. Dental Materials 16:145-149 2000

Heshmati RH, Nagy WW, Wirth CG, Dhuru VB: Delayed linear expansion of improved dental stone. Journal of Prosthetic Dentistry 88:26-31, 2002. 


\title{
CURRICULUM VITAE
}

\author{
Marcos Cid Galano
}

\section{EDUCATION}

$\begin{array}{lll}\text { Marshall University } & \text { No Degree } & 1992-1995 \\ \text { West Virginia University } & \text { D.D.S. } & 2000 \\ \text { West Virginia University } & \text { M.S. } & 2003 \\ \text { West Virginia University } & \begin{array}{l}\text { Certificate in } \\ \text { Prosthodontics }\end{array} & 2003\end{array}$

